\title{
Ex vivo normothermic perfusion of isolated segmental porcine bowel: a novel functional model of the small intestine
}

\author{
M. O. Hamed ${ }^{1, *}$, A. D. Barlow ${ }^{1}$, N. Dolezalova ${ }^{1}$, S. Khosla ${ }^{2}$, A. Sagar ${ }^{2}$, F. M. Gribble ${ }^{3}$, S. Davies ${ }^{3}$, M. P. Murphy ${ }^{4}$,S. A. Hosgood ${ }^{1}$, \\ M. L. Nicholson ${ }^{1}$ and K. Saeb-Parsy ${ }^{1}$ \\ ${ }^{1}$ Department of Surgery, University of Cambridge, and NIHR Cambridge Biomedical Research Campus, Cambridge, UK \\ ${ }^{2}$ Wellcome Trust - MRC Institute of Metabolic Science, University of Cambridge, Cambridge, UK \\ ${ }^{3}$ Department of Histopathology, University of Cambridge, Cambridge, UK \\ ${ }^{4}$ MRC Mitochondrial Biology Unit, Cambridge, UK \\ *Correspondence to: Department of Surgery, Addenbrookes Hospital, Hills Road, Cambridge, CB2 OQQ UK \\ (e-mail:mazin_hamed@hotmail.com)
}

\begin{abstract}
Background: There is an unmet need for suitable ex vivo large animal models in experimental gastroenterology and intestinal transplantation. This study details a reliable and effective technique for ex vivo normothermic perfusion (EVNP) of segmental porcine small intestine.

Methods: Segments of small intestine, 1.5-3.0 $\mathrm{m}$ in length, were retrieved from terminally anaesthetized pigs. After a period of cold ischaemia, EVNP was performed for $2 \mathrm{~h}$ at $37^{\circ} \mathrm{C}$ with a mean pressure of $80 \mathrm{mmHg}$ using oxygenated autologous blood diluted with Ringer's solution. The duration of EVNP was extended to $4 \mathrm{~h}$ for a second set of experiments in which two segments of proximal to mid-ileum (1.5-3.0 m) were retrieved from each animal and reperfused with whole blood (control) or leucocyte-depleted blood to examine the impact of leucocyte depletion on reperfusion injury.

Results: After a mean cold ischaemia time of $5 \mathrm{~h}$ and $20 \mathrm{~min}$, EVNP was performed in an initial group of four pigs. In the second set of experiments, five pigs were used in each group. In all experiments bowel segments were well perfused and exhibited peristalsis during EVNP. Venous glucose levels significantly increased following luminal glucose stimulation (mean(s.e.m.) basal level 1.8(0.6) $\mathrm{mmol} / \mathrm{l}$ versus peak $15.5(5.8) \mathrm{mmol} / \mathrm{l} ; \mathrm{P}<0.001$ ) and glucagon-like peptide 1 (GLP-1) levels increased in all experiments, demonstrating intact absorptive and secretory intestinal functions. There were no significant differences between control and leucocyte-depleted animals regarding blood flow, venous glucose, GLP-1 levels or histopathology at the end of $4 \mathrm{~h}$ of EVNP.
\end{abstract}

Conclusions: This novel model is suitable for the investigation of gastrointestinal physiology, pathology and ischaemia reperfusion injury, along with evaluation of potential therapeutic interventions.

\section{Introduction}

There is increasing appreciation of the multitude of complex physiological roles of the intestine, both in health and in disease. These include the involvement of enteroendocrine cells in the regulation of appetite, gut motility and insulin secretion ${ }^{1}$; the interplay between intestinal immune cells, the microbiota and inflammation ${ }^{2}$; and the functions of regulatory cell populations in maintaining the immune tolerance of the intestinal mucosa ${ }^{3}$. Optimal study of such complex biological processes requires access to functional experimental models amenable to close monitoring and manipulation. Much of the experimental data in these areas currently derives from small animal models, in part due to lack of appropriate ex vivo large animal models. While informative, extrapolation and direct clinical translation of experimental findings from small animals to humans is inherently challenging.

The last decade has also seen a dramatic increase in small bowel transplantation as a treatment option for patients with short bowel syndrome who have failed parenteral nutrition, either due to loss of vascular access or irreversible liver damage. Short-term outcomes have steadily improved and 1-year patient survival after isolated small bowel transplantation is now approximately 80 per cent ${ }^{4}$. Long-term outcomes, however, remain poor with little improvement in recent years, probably reflecting combinations of ischaemia-reperfusion (IR) injury, rejection, infection and graft-versus-host disease. If long-term results are to be improved, it is vital that appropriate functional large animal models are available to allow investigation of the mechanisms underlying these processes in order to identify and evaluate potential interventions.

Blood-based ex vivo normothermic perfusion (EVNP) has been shown to be a suitable technique for the study of isolated organs under controlled perfusion conditions. Such a model, when optimized, can potentially enable investigation of IR injury, organ physiology and possible therapeutic strategies. Reliable EVNP 


\section{Surgical relevance}

Despite increasing recognition of the utility of ex vivo normothermic perfusion (EVNP) as an experimental and clinical technique, there are no widely adopted methods for perfusion of intestinal segments. A successful technique is described. Beyond its potential utility in investigation of intestinal physiology, function and pathology, such a validated experimental model could have applications to the field of intestinal transplantation where long-term outcomes remain poor. Ischaemia-reperfusion injury, rejection, infection and graft-versus-host disease all play a role, and a segmental intestine EVNP model could potentially allow investigation of the mechanisms underlying these pathologies and allow possible interventions to be investigated.

models using a blood-based solution have been established in large animals or humans for kidney ${ }^{5,6}$, liver $^{7,8}$, heart ${ }^{9,10}$ and lung $^{11,12}$. In addition to being a useful tool for research, EVNP has been shown to have therapeutic benefit in improving function of marginal human kidneys ${ }^{13}$ and livers ${ }^{14}$. The potential utility of EVNP for the functional study of human pancreases has also been reported ${ }^{15}$. The aim of this study was therefore to examine the feasibility of EVNP of isolated porcine small bowel segments as a similar experimental model.

Previous EVNP studies of pig and human kidney kidneys have demonstrated that depletion of leucocytes prior to perfusion can ameliorate IR injury ${ }^{16,17}$. As leucocytes are a source of reactive oxygen species production ${ }^{18,19}$, this may partially explain the protective effect of leucocyte depletion in these studies. Therefore, a second aim of the current study was to examine the impact of leucocyte depletion on small bowel IR injury using this model.

\section{Methods}

\section{Small intestine retrieval}

Approval for the study was granted under the UK Animal (Scientific Procedures) Act 1986. Nine young adult male white pigs (50-60 kg; $\mathrm{n}=9$ ) were used. A midline laparotomy was performed under general anaesthesia. Following systemic anticoagulation with 25000 units of unfractionated heparin sodium in $5 \mathrm{ml}$ of solution (Wockhardt UK Ltd, Wrexham, UK) the distal aorta was cannulated with a 14 French Soft-Flow ${ }^{\circledR}$ arterial cannula (Medtronic UK, Watford, UK). The pig was then exsanguinated via the aortic cannula and the blood collected into a sterile receptacle. Asystole was confirmed, the descending thoracic aorta crossclamped and in situ perfusion initiated with 2 litres of hyperosmolar citrate solution (Soltran ${ }^{\circledR}$; Baxter Healthcare, Thetford, UK) followed by 2 litres of University of Wisconsin solution (CoStorSol ${ }^{\circledR}$; Bridge To Life, London, UK). The abdomen was packed with crushed ice to aid organ cooling. Once cold perfusion was complete, segments of proximal to mid-ileum (1.5-3.0 m) were isolated and resected with intact mesenteric vascular arcades suitable for cannulation. Those segments of small bowel were then stored in cooled hyperosmolar citrate solution (Soltran ${ }^{\circledR}$, Baxter Healthcare, Thetford, UK) and transported in crushed ice at $4^{\circ} \mathrm{C}$. To examine the impact of perfusion with leucocyte-depleted blood on IR injury, two consecutive $1.5-\mathrm{m}$ segments of small intestine were retrieved from each of five pigs in the second sets of experiments.

\section{EVNP circuit}

A customised EVNP circuit based on commercially available paediatric cardiopulmonary bypass was used (Medtronic UK, Watford, UK). The system consisted of an organ chamber, venous reservoir, centrifugal blood pump, membrane oxygenator and heat exchanger. The perfusate contained autologous porcine whole or leucocyte-depleted blood mixed with Ringer's solution for infusion ${ }^{\mathrm{TM}}$ (Baxter Healthcare, Thetford, UK), cefuroxime (Zinacef $^{\circledR}$, GlaxoSmithKline, Brentford, UK), 8.4 per cent sodium bicarbonate $^{\text {TM }}$ (Sigma-Aldrich, Gillingham, UK) and 5 per cent glucose w/v Intravenous Infusion ${ }^{\mathrm{TM}}$ (Baxter Healthcare, Thetford, UK). After a period of cold ischaemia, benchwork was performed with the organ cooled on ice. The proximal mesenteric artery was cannulated using a 14 French Soft-Flow ${ }^{\circledR}$ arterial cannula (Pennine Healthcare, Derby, UK), the distal artery was ligated and the graft flushed with Gelofusine ${ }^{\circledR}$ (Braun Medical, Sheffield, UK). The proximal lumen of the bowel segment was also cannulated. Continuous (non-pulsatile) perfusion was performed at $37^{\circ} \mathrm{C}$ with a mean pressure of $80 \mathrm{mmHg}$ for $2 \mathrm{~h}$ in the first series of experiments to validate segmental intestine EVNP, and extended to $4 \mathrm{~h}$ in the second series of experiments to examine the impact of leucocyte depletion on reperfusion injury using a white cell filter (LeukoGuard ${ }^{\circledR}$ RS; Pall Medical, Portsmouth, UK).

\section{Outcome measures}

Readings were taken for blood flow ( $\mathrm{ml} / \mathrm{min})$, mean arterial pressure (mmHg), pump speed (RPM) and temperature throughout the perfusion. The bowel was visually assessed for quality of perfusion, including to the mucosa, mucosal oedema and peristalsis. Random small bowel biopsy specimens were taken at the end of cold ischaemia and the end of EVNP for histological assessments to determine the severity of IR injury.

\section{Luminal glucose stimulation}

In the first series of experiments, after a 60-min equilibration period, $50 \mathrm{ml}$ of warmed 20 per cent glucose (D-(+)-Glucose, Dextrose $^{\mathrm{TM}}$, Sigma Aldrich, Poole, UK) was infused over $1 \mathrm{~min}$ into the bowel lumen. In the second series of experiments, small bowel segments were infused with $50 \mathrm{ml}$ of warmed solution of 20 per cent glucose (D-(+)-Glucose, Dextrose ${ }^{\mathrm{TM}}$, Sigma Aldrich, Poole, UK) over 1 min after $1 \mathrm{~h}$ and $4 \mathrm{~h}$ of EVNP. Venous samples were taken at 0, 1, 5 and 10 min after finishing the first and second infusion. Glucose levels were determined by electrochemical means (Accu-Chek ${ }^{\circledR}$ Aviva; Roche Diagnostics, Burgess Hill, UK). Total glucagon-like peptide-1 (GLP-1) levels were determined by a two-site microtitre plate-based immunoassay with electrochemical luminescence detection using a Meso Scale Discovery kit (Gaithersburg, Maryland, USA).

\section{Histopathology}

A full-thickness biopsy specimen was taken from the isolated segments of small bowel at different times (in situ, end of cold ischaemic time and end of EVNP). The collected specimens were fixed in 10 per cent formalin, processed to paraffin, sectioned at $4 \mu \mathrm{m}$ and stained with haematoxylin and eosin. Samples were assessed for markers and degrees of IR injury. Histopathological 
assessment was performed blinded to experimental group identity. Histopathological assessment was based on villus height, surface epithelial appearance, neutrophil infiltration and presence of intra-epithelial lymphocytes, scored individually in each intestinal sample (Table 1).

\section{Statistical analysis}

Data are presented as mean(s.e.m.) unless otherwise stated. Statistical analysis was performed using GraphPad Prism ${ }^{\circledR}$ (version 8.4; GraphPad, La Jolla, CA) and differences between time points were analysed using non-parametric Friedman test or Kruskal-Wallis test (in case of missing values), both followed by Dunn's multiple comparison test if significant. Small bowel segments were randomly assigned to control and leucocyte-depletion arms in the second series of experiments. The differences between time points were analysed using non-parametric Friedman test followed by Dunn's multiple comparison test. The difference between the control and the leucocyte-depleted group at the final time point was analysed using the two-tailed Wilcoxon test.

Table 1 Histopathological scoring system for intestine ischaemia-reperfusion injury

\begin{tabular}{|c|c|c|c|c|}
\hline Score & Villus height & Surface epithelium & Neutrophil infiltration & Intra-epithelial lymphocytes \\
\hline 0 & Normal & Intact & None & Normal \\
\hline 1 & Some blunting & Degenerate changes & Localized in lamina propria & Focal increase \\
\hline 2 & Partial atrophy & Some loss & Focal crypt & Diffuse increase \\
\hline 3 & Subtotal atrophy & Substantial loss & Multifocal crypt & \\
\hline 4 & Lost & Ulceration & Crypt abscess & \\
\hline
\end{tabular}

The total scale score ranges from 0 to 14, with 0 representing no pathological changes, 7 moderate changes and 14 severe pathological changes.

a

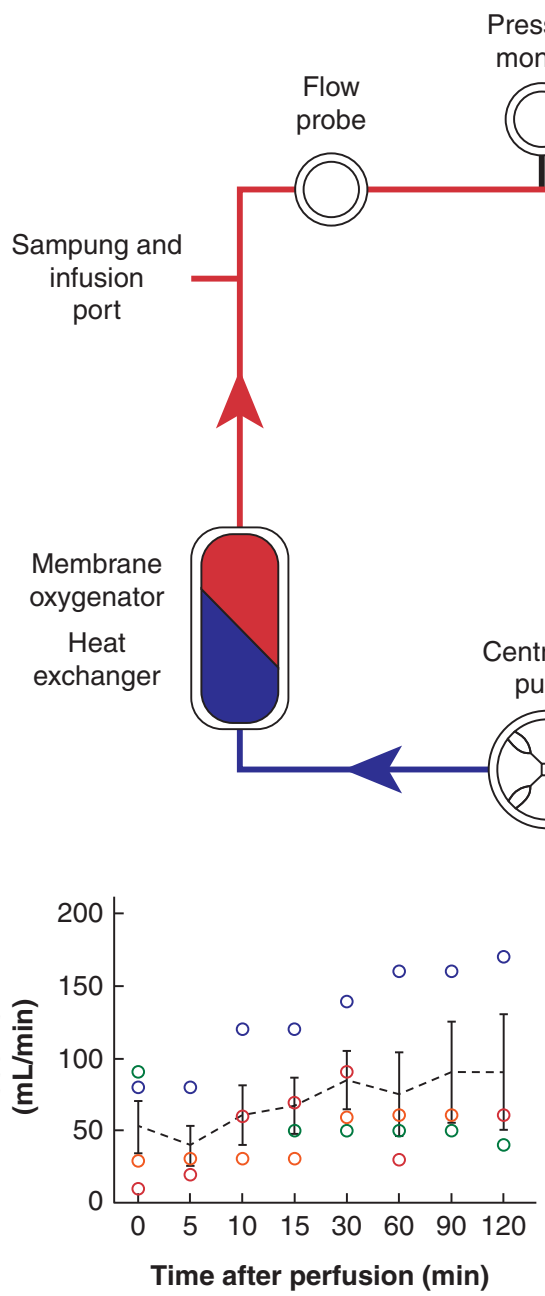

Pressure

monitor
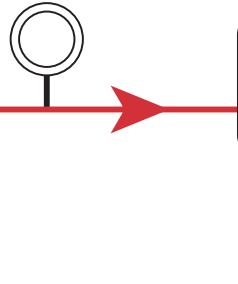

entrifugal<smiles>[PbH]</smiles>

Organ

chamber

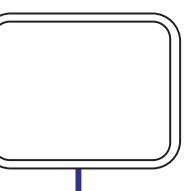

b

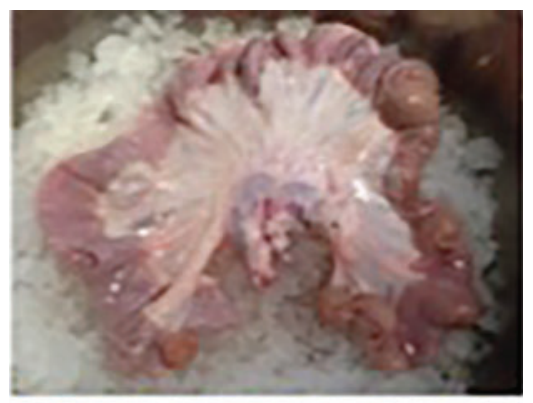

C

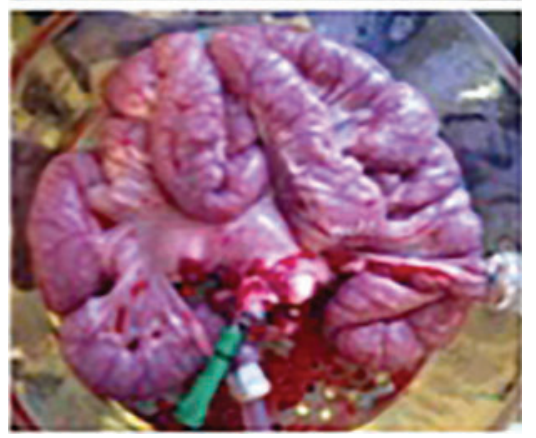

f

Time after luminal stimulation (min)

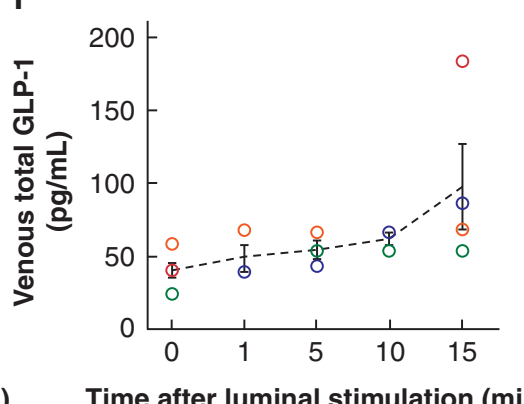

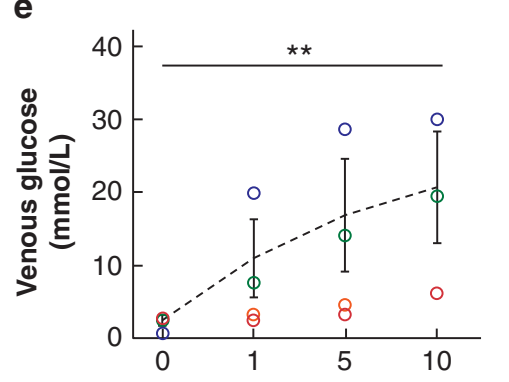

Time after luminal stimulation ( $\mathrm{min})$

Fig. 1 Ex vivo normothermic perfusion of isolated small bowel segments

a The ex vivo normothermic perfusion (EVNP) circuit utilizes paediatric venous bypass technology to perfuse isolated organs with normothermic oxygenated blood. Representative appearance of intestinal segments $\mathbf{b}$ before and c 30 min after perfusion on the EVNP circuit. $\mathbf{d}$ Blood flow through the intestine segment stabilized within 10 min of reperfusion. e Mean(s.e.m.) venous glucose in the EVNP circuit increased rapidly following administration of 20 per cent glucose into the lumen of the intestine from $1.8(0.6) \mathrm{mmol} / \mathrm{l}$ to a peak of 15.5(5.8) mmol/1, $\mathrm{P}=0.010$ (Friedman test followed by Dunn's correction for multiple comparisons). f Following luminal glucose stimulation, total GLP-1 levels increased from a mean(s.e.m.) of 41.3(6.9) pg/ml to 98.0(29.4) pg/ml. Data are mean(s.e.m.); ${ }^{* *}$ P $\leq$ 0.01. 

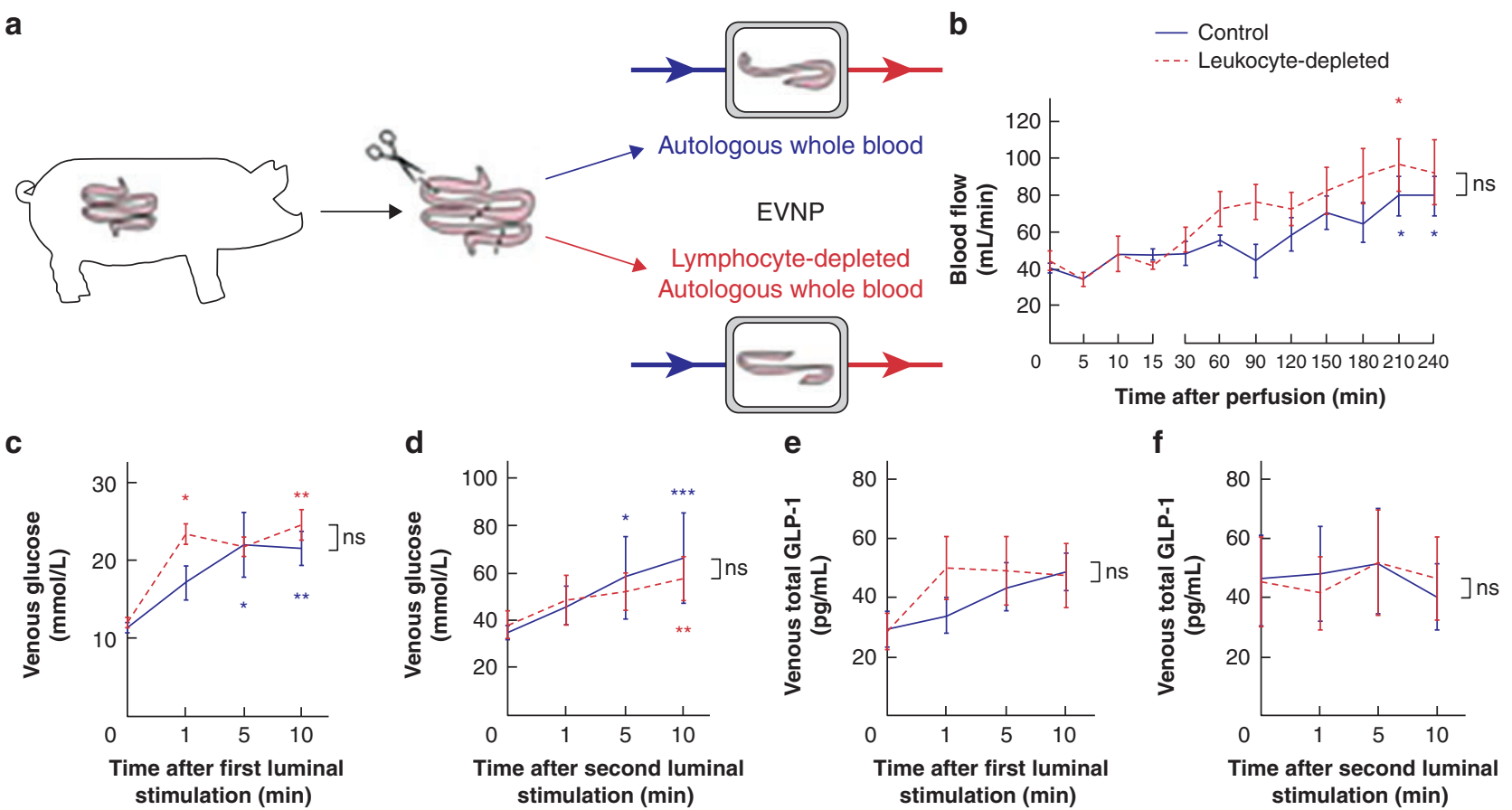

Fig. 2 Impact of leucocyte depletion on intestine functional parameters on ex vivo normothermic perfusion

a Two segments of proximal to mid-ileum were retrieved from anesthetized pigs and transported in Soltran at $4^{\circ} \mathrm{C}$. Intestine segments were placed simultaneously on two ex vivo normothermic perfusion (EVNP) circuits and perfused with either autologous whole blood (control) or autologous whole blood depleted of lymphocytes (leucocyte and leucocyte-depleted). $\mathbf{b}$ There was no significant difference in the blood flow at the end of $4 \mathrm{~h}$ of EVNP between the control ( $\mathrm{n}=5$ ) and the leucocyte-depleted $(n=5)$ groups. c Following the first intraluminal 20 per cent glucose infusion after 60 min of EVNP, mean(s.e.m.) venous glucose levels increased significantly compared to baseline levels both in the control group (21.6(2.2) $\mathrm{mmol} / \mathrm{l}$ versus $11.6(0.7) \mathrm{mmol} / 1$; $\mathrm{P}=0.043)$ and the leucocyte-depleted group (24.7(1.9) mmol/l versus $12.0(0.6) \mathrm{mmol} / \mathrm{l} ; \mathrm{P}=0.008$; Friedman test followed by Dunn's multiple comparisons correction). c There were no significant differences in venous glucose levels between the control and leucocyte-depleted groups after first luminal glucose stimulation or $\mathbf{d}$ after the second luminal glucose stimulation at the end of $4 \mathrm{~h}$ of EVNP. Venous total GLP-1 levels following 20 per cent glucose infusion were similar in the control and leucocyte-depleted groups e after 60 min or $4 \mathrm{~h}$ of EVNP. Data are mean \pm s.e.m.; ${ }^{*} P \leq 0.05,{ }^{* *} P \leq 0.01,{ }^{* * *} P \leq 0.001$.

\section{Results}

\section{Validation of segmental intestine EVNP}

To validate segmental intestinal EVNP, one segment of small intestine was retrieved from each pig and perfused with autologous blood on the EVNP circuit (Fig. 1a). The mean warm ischaemic time, defined as the time between asystole and perfusion with cold preservation solution, was $4.8 \mathrm{~min}$ (range 2-10 min). The mean cold ischaemic time before the onset of EVNP was $5 \mathrm{~h}$ $20 \mathrm{~min}$ (range $3 \mathrm{~h} 42 \mathrm{~min}$ to $6 \mathrm{~h} 39 \mathrm{~min}$ ). The cold ischaemic time was the time taken for transport from the pig facility to the experimental laboratory, as well as the time taken to surgically prepare the intestinal segments for EVNP. All segments of bowel $(n=4)$ were successfully perfused with no technical failures. All bowel segments appeared well perfused with viable, nonhaemorrhagic mucosa throughout the perfusion with no deterioration in the appearance of the organ at the end of the experiment (Fig. 1b,c). Peristalsis was observed in all four bowel segments (Video S1).

Mean(s.e.m.) blood flow during EVNP was 72(7.9) $\mathrm{ml} / \mathrm{min}$ (Fig. 1d). There was no difference in the blood flow between animals and no deterioration in flow during the course of the perfusion. After 60 min of EVNP and 20 per cent glucose infusion there was a rapid rise in venous glucose (Fig. 1e; less than 10 mins) and GLP-1 (Fig. 1f; less than 15 mins).

\section{Impact of leucocyte depletion on reperfusion injury}

The mean warm ischaemic time was 2.6 (range 2-4) min. The mean cold ischaemic time before the onset of EVNP was $2 \mathrm{~h}$
57 min (range 2 h 36 min to 3 h $36 \mathrm{~min}$ ). All segments of bowel $(n=10)$ were successfully perfused with no technical failures (Fig. 2a). All bowel segments appeared well perfused with viable, non-haemorrhagic mucosa throughout the perfusion, with no deterioration in the appearance of the organ at the end of the experiment.

There was no significant difference in the blood flow at the end of $4 \mathrm{~h}$ of EVNP between the control and leucocyte-depleted groups (Fig. 2b). Following the first intraluminal 20 per cent glucose infusion after 60 min of EVNP, venous glucose levels increased significantly compared to baseline levels both in the control and the leucocyte-depleted groups (Fig. 2c). There were no significant differences in venous glucose levels between the control and leucocyte-depleted groups at 10 minutes after the first luminal stimulation (Fig. 2c). When absorptive function of the small intestine was tested again at the end of the $4 \mathrm{~h}$ of EVNP with a second intraluminal 20 per cent glucose infusion, when baseline venous glucose concentrations were higher, there were still no significant differences in venous glucose levels between the control and leucocyte-depleted group at 10 minutes after the second luminal stimulation (Fig. 2d).

Venous total GLP-1 levels were similar between the control and leucocyte-depleted groups following the first intraluminal 20 per cent glucose infusion after 60 minutes EVNP (Fig. 2e) and following the second intraluminal 20 per cent glucose infusion at the end of $4 \mathrm{~h}$ of EVNP (Fig. 2f).

\section{Histological assessment}

Representative images of mild, moderate and severe degrees of injury scored according the presence of pathological changes in 
a
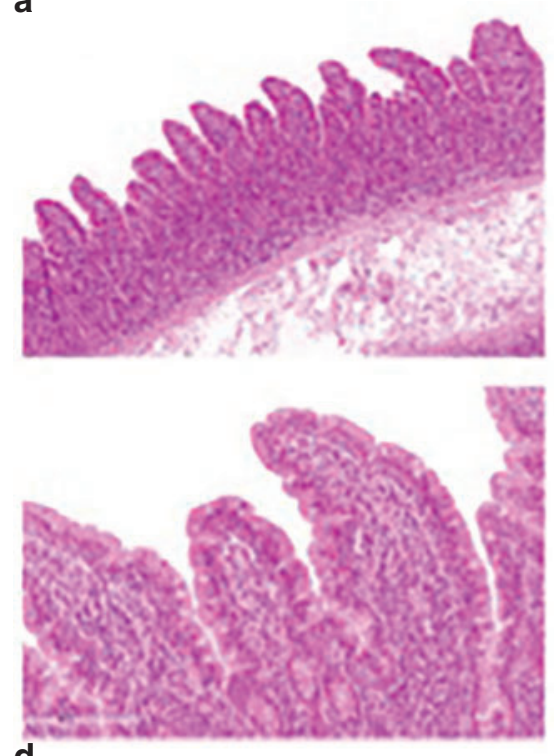

d

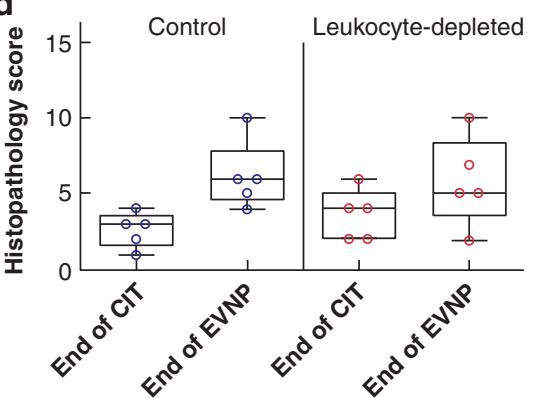

b
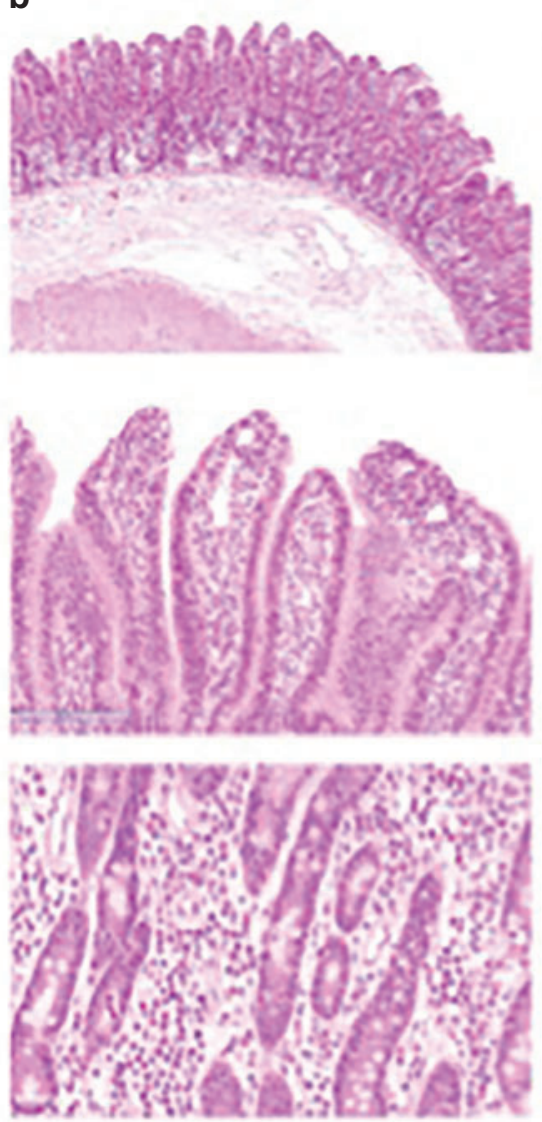

C
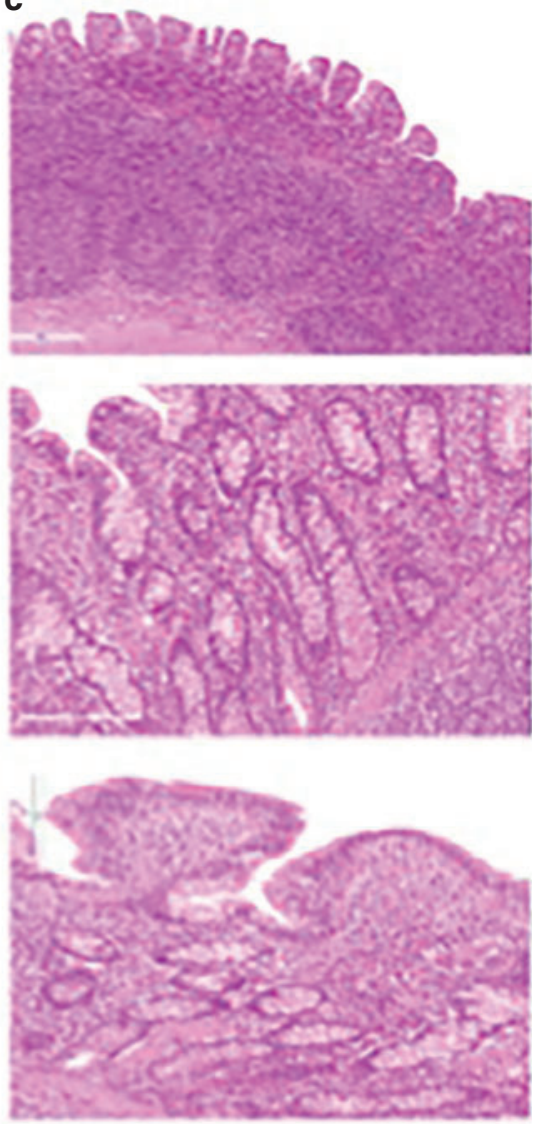

Fig. 3 Histological assessment of small bowel tissue biopsy specimens

a Low-grade injury (total score 1): top - normal villus height, normal surface epithelium and no neutrophil infiltration (haematoxylin and eosin (H\&E) $\times 4$ ); bottom focal increase in intra-epithelial lymphocytes; score 1 (H\&E $\times 20)$. b Moderate-grade injury (total score 5): top - normal villus height and no neutrophil infiltration $(\mathrm{H} \& \mathrm{E} \times 4)$; middle - substantial loss of surface epithelium; score 3 (H\&E $\times 20$ ); bottom - diffuse increase of intra-epithelial lymphocytes; score 2 (H\&E $\times 20)$. c Highgrade injury (total score 11): top - some blunting in villus height; score 1 and ulceration of surface epithelium; score 4 (H\&E $\times 4$ ); middle - crypt abscess of neutrophil infiltration; score 4 (H\&E $\times 20)$; bottom - diffuse increase of intra-epithelial lymphocytes; score 2 (H\&E $\times 20)$. (D) There were no significant differences between the control group $(\mathrm{n}=5)$ and the leucocyte-depleted group $(\mathrm{n}=5)$ in the mean(s.e.m.) histopathology injury score for the small bowel tissue biopsy specimens at the end of the cold ischaemic time (CIT) (2.6(0.5) versus 3.6(0.7); $P=0.999)$ or after EVNP $(6.2(1.0)$ versus 5.8(1.3) $P=0.999 ;$ Friedman test followed by Dunn's correction for multiple comparisons). There was no significant difference between the end of CIT and end of EVNP in both the control group ( $\mathrm{P}=0.165)$ and the leucocyte-depleted group ( $P=0.850$, Friedman test followed by Dunn's correction for multiple comparisons). Boxplot whiskers indicate minimum and maximum values.

villus height, surface epithelium, neutrophil infiltration and intra-epithelial lymphocytes are shown in Fig. 3a-c. AT the end of $4 \mathrm{~h}$ of EVNP, there were no significant differences between the control group and the leucocyte-depleted groups in the histopathology injury score for the small bowel tissue biopsy specimens at the end of the cold ischaemic time or after EVNP (Fig. 3d).

\section{Discussion}

These experiments provide proof-of-concept evidence that bloodbased EVNP of porcine small bowel segments can be used to evaluate intestinal physiology, IR injury and pharmacology, including drug absorption and therapeutic efficacy. The studies also demonstrated that it is possible to obtain two consecutive segments of small intestine from the same pig for simultaneous perfusion on two EVNP circuits, enabling segments of small intestine from the same animal to be used in both the control and treatment experimental arms.

No apparent differences between the consecutive segments of the small intestine obtained from the same pig were observed, acknowledging that detailed physiological or histological comparisons were not undertaken. While recognizing that small intestine anatomy and physiology changes along its length, it is important that comparative experiments incorporate randomization of proximal and distal segments to treatment and control groups. It would be possible with the present system to reduce the length of the intestine segment perfused to minimize variation in function between intestinal segments.

Increases in venous glucose and GLP-1 were seen consistently following luminal glucose administration $60 \mathrm{~min}$ after the start of EVNP. Although intraluminal stimulation with a glucose-depleted control was not performed, the rapid time course and magnitude of the response is consistent with specific responses to stimulation. Glucose is actively absorbed from the intestine into the blood by sodium-glucose transporter 1 (SGLT1) ${ }^{20}$ and glucose transporter type $2^{21}$. GLP-1 is an incretin produced from intestinal L cells, that potentiates glucose-stimulated insulin secretion by pancreatic $\beta$ cells. Glucose-stimulated GLP-1 secretion into the blood is an active process, potentially also mediated via SGLT1 ${ }^{22}$. The present results demonstrate both active intestinal absorption and secretion during EVNP, confirming cellular viability and function. 
In the existing model, the use of short bowel segments and a circulating volume of $500 \mathrm{ml}$ potentially allows three or four different experiments from a single pig, reducing costs and facilitating comparative experiments on different segments of the bowel. It also enables the efficacy of a therapeutic intervention to be compared to a control using two or more intestine segments from the same pig and after identical warm and cold ischaemic periods. Perfusion of small intestine segments with autologous blood may be critical as previous studies using allogenic blood ${ }^{23-}$ ${ }^{28}$ reported significant mucosal sloughing and increasing perfusion pressures, up to $200 \mathrm{mmHg}$, to maintain blood flow during EVNP. The mucosa in all segments in the present experiments remained pink and normal in appearance, with no evidence of haemorrhage or sloughing.

There have been occasional reports of blood-based EVNP of small bowel segments in dogs ${ }^{29,30}$ and humans ${ }^{31,32}$. Unlike pigs, availability, cost and ethical concerns preclude their large-scale experimental utility.

There were no significant differences between the control group perfused with whole blood and the leucocyte-depleted group in terms of blood flow, venous glucose, GLP-1 levels or histopathology at the end of $4 \mathrm{~h}$ of EVNP. The absence of a demonstrable protective effect in the leucocyte-depleted group might be partially explained by the short duration of EVNP (4 h). In addition, small bowel segments on the EVNP were not exposed to systemic neurohormonal and immunological factors that influence the severity of IR injury in clinical practice. Notwithstanding the potential effects on cellular or immune markers that were not assessed, the present study showed that, unlike kidneys undergoing EVNP ${ }^{16,17}$, leucocyte depletion had no clear short-term functional or histological effect on intestinal segments. The shorter cold ischaemic times achieved in this series compared to earlier validation studies were due to optimization of the surgical technique for preparation of the intestine segments for EVNP.

Beyond the current experiments, significant refinements can still be made to the retrieval technique and perfusion conditions that should allow prolonged perfusion and more detailed assessment of intestinal function and viability. The technique, however, provides a cost-effective, practical and reliable model for the study of intestinal physiology, pharmacology and transplantation.

\section{Acknowledgement}

M.O.H. and A.D.B. contributed equally to this work.

Disclosure. The authors declare no conflict of interests.

\section{Supplementary material}

Supplementary material is available at BJS Open online.

\section{References}

1. Parker HE, Gribble FM, Reimann F. The role of gut endocrine cells in control of metabolism and appetite. Exp Physiol 2014;99: 1116-1120

2. Cox AJ, West NP, Cripps AW. Obesity, inflammation, and the gut microbiota. Lancet Diabetes Endocrinol 2015;3:207-215

3. Chai JN, Zhou YW, Hsieh CS. T cells and intestinal commensal bacteria-ignorance, rejection, and acceptance. FEBS Lett 2014; 588:4167-4175
4. Grant D, Abu-Elmagd K, Mazariegos G, Vianna R, Langnas A, Mangus $R$ et al. Intestinal transplant registry report: global activity and trends. Am J Transplant 2015;15:210-219

5. Hosgood SA, Randle LV, Patel M, Watson CJ, Bradley JA, Nicholson ML. Sildenafil citrate in a donation after circulatory death experimental model of renal ischemia-reperfusion injury. Transplantation 2014;98:612-617

6. Yates PJ, Hosgood SA, Nicholson ML. Leukocyte and platelet depletion improves blood flow and function in a renal transplant model. J Surg Res 2012;172:159-164

7. Minor T, Efferz P, Fox M, Wohlschlaeger J, Luer B. Controlled oxygenated rewarming of cold stored liver grafts by thermally graduated machine perfusion prior to reperfusion. Am J Transplant 2013;13:1450-1460

8. Nassar A, Liu Q, Farias K, D’Amico G, Tom C, Grady P et al. Ex vivo normothermic machine perfusion is safe, simple, and reliable: results from a large animal model. Surg Innou 2015;22 61-69

9. Trahanas JM, Witer LJ, Alghanem F, Bryner BS, Iyengar A, Hirschl JR et al. Achieving 12 hour normothermic ex situ heart perfusion: an experience of 40 porcine hearts. ASAIO J 2016;62: 470-476

10. Church JT, Alghanem F, Deatrick KB, Trahanas JM, Phillips JP, Hee Song $M$ et al. Normothermic ex vivo heart perfusion: effects of live animal blood and plasma cross circulation. ASAIO J 2017; 63:766-773

11. Nelson K, Bobba C, Ghadiali S, Hayes D Jr, Black SM, Whitson BA. Animal models of ex vivo lung perfusion as a platform for transplantation research. World J Exp Med 2014;4:7-15

12. Hsin $M, A u T$. Ex vivo lung perfusion: a potential platform for molecular diagnosis and ex vivo organ repair. J Thorac Dis 2018; 10:s1871-s1883

13. Nicholson ML, Hosgood SA. Renal transplantation after ex vivo normothermic perfusion: the first clinical study. Am J Transplant 2013;13:1246-1252

14. Nasralla D, Coussios CC, Mergental H, Akhtar MZ, Butler AJ, Ceresa CDL et al.; for the Consortium for Organ Preservation in Europe. A randomized trial of normothermic preservation in liver transplantation. Nature 2018;557:50-56

15. Barlow AD, Hamed MO, Mallon DH, Brais RJ, Gribble FM, Scott MA et al. Use of ex vivo normothermic perfusion for quality assessment of discarded human donor pancreases. Am J Transplant 2015;15:2475-2482

16. Harper S, Hosgood S, Kay M, Nicholson M. Leucocyte depletion improves renal function during reperfusion using an experimental isolated haemoperfused organ preservation system. $\mathrm{Br} J$ Surg 2006;93:623-629

17. Hosgood SA, Patel M, Nicholson ML. The conditioning effect of ex vivo normothermic perfusion in an experimental kidney model. J Surg Res 2013;182:153-160

18. Robinson JM. Reactive oxygen species in phagocytic leukocytes. Histochem Cell Biol 2008;130:281-297

19. Nguyen GT, Green ER, Mecsas J. Neutrophils to the ROScue: mechanisms of NADPH oxidase activation and bacterial resistance. Front Cell Infect Microbiol 2017;7:373

20. Faust RG, Leadbetter MG, Plenge RK, McCaslin AJ. Active sugar transport by the small Intestine: the effects of sugars, amino acids, hexosamines, sulfhydryl-reacting compounds, and cations on the preferential binding of D-glucose to Tris-disrupted brush borders. J Gen Physiol 1968;52:482-494

21. Kellett GL, Brot-Laroche E. Apical GLUT2: a major pathway of intestinal sugar absorption. Diabetes 2005;54:3056-3062 
22. Kuhre RE, Frost CR, Svendsen B, Holst JJ. Molecular mechanisms of glucose-stimulated GLP-1 secretion from perfused rat small intestine. Diabetes 2015;64:370-382

23. Braun F, Hosseini M, Wieland E, Sattler B, Laabs S, Lorf $T$ et al. Expression of E-selectin and its transcripts during intestinal ischemia-reperfusion injury in pigs. Transplantation Proc 2004;36: 265-266.

24. Cosse C, Sabbagh C, Kamel S, Galmiche A, Regimbeau J-M. Procalcitonin and intestinal ischemia: a review of the literature. World J Gastroenterol 2014;20:17773-17778

25. Braun F, Hosseini M, Wieland E, Sattler B, Muller AR, Fandrich F et al. Kinetics and localization of interleukin-2, interleukin-6, heat shock protein 70, and interferon gamma during intestinalreperfusion injury. Transplant Proc 2004;36:267-269

26. Braun F, Hosseini SM, Lorf T, Laabs S, Ringe B. Differential gene expression during intestinal ischemia-reperfusion injury. Transplant Proc 2002;34:2301-2302

27. Braun F, Quondamatteo F, Bothuri P, Hosseini M, Laabs S, Sattler B et al. Determination of intestinal alpha-glutathione
S-transferase after ischemia-reperfusion injury. Acta Gastroenterol Belg 1999;62:229-233

28. Braun F, Schutz E, Laabs S, Hanack U, Sattler B, Lorf T et al. Development of a porcine small bowel ex vivo perfusion model. Transplant Proc 1998;30:2613-2615

29. Kachelhoffer J, Mendel C, Dauchel J, Hohmatter D, Grenier JF. The effects of VIP on intestinal motility: study on ex vivo perfused isolated canine jejunal loops. Digest Dis Sci 1976;21: 957-962

30. Walker WA, Strodel WE, Eckhauser FE, Heldsinger A, Vinik AI. Enterooxyntin release from isolated perfused canine jejunum. J Surg Res 1983;34:486-492

31. Desai TR, Sisley AC, Brown S, Gewertz BL. Defining the critical limit of oxygen extraction in the human small intestine. J Vasc Surg 1996;23:832-838

32. Wyble CW, Desai TR, Clark ET, Hynes KL, Gewertz BL. Physiologic concentrations of TNFalpha and IL-1beta released from reperfused human intestine upregulate E-selectin and ICAM-1. J Surg Res 1996;63:333-338 